\title{
Espectrorradiometria de solos e comparação com sensores orbitais
}

\author{
Aline Marques Genú $\left({ }^{1 *}\right)$; José A. M. Demattê $\left({ }^{2}\right)$ \\ (') Universidade Estadual do Centro-Oeste (Unicentro), Departamento de Agronomia, Rua Simeão Camargo Varela de Sá, 03, \\ 85040-080 Guarapuava (PR), Brasil. \\ (2) Universidade de São Paulo, Escola Superior de Agricultura “Luiz de Queiroz” (ESALQ), Departamento de Ciência do Solo, \\ Caixa Postal 09, 13418-900 Piracicaba (SP), Brasil. \\ (*) Autora correspondente: agenu@unicentro.br
}

Recebido: 25/fev./2011; Aceito: 26/set./2011

\section{Resumo}

Este trabalho teve por objetivo caracterizar e comparar o comportamento espectral de diferentes classes de solo obtidos de sensores orbitais e terrestres. Para tanto, em Rafard (SP), uma área de 184 ha foi estaqueada em grade regular de $100 \times 100$ m e amostras de solo foram coletadas e seus pontos georreferenciados. Posteriormente, foram obtidas as curvas espectrais das amostras com o sensor IRIS e os pontos amostrais, sobrepostos às imagens Landsat e ASTER da área para coleta dos dados espectrais orbitais. Na sequência, as amostras de terra foram divididas por classe de solo e geradas curvas espectrais médias, por classe de solo, para todos os sensores. Verificou-se que essas classes foram diferenciadas pela textura, matéria orgânica e pelo ferro total para todos os sensores estudados, ressaltando-se que os sensores orbitais, apesar da menor resolução espectral, mantiveram as características das curvas de solo quanto à intensidade de reflectância.

Palavras-chave: sensoriamento remoto, pedologia, atributos do solo.

\section{Spectroradiometry of soil and comparison with orbital sensors}

\section{Abstract}

The aim of this study was to characterize and compare the spectral behavior of different soil classes obtained by orbital and terrestrial sensors. For this, an area of 184 ha in Rafard (SP) Brazil was staked on a regular grid of $100 \times 100$ m and soil samples were collected and georeferenced. After that, soil spectral curves were obtained with IRIS sensor and the sample points were overlaid at Landsat and ASTER images for spectral data collection. The soil samples were classified and mean soil curves for all sensors were generated by soil classes. The soil classes were differentiated by texture, organic matter and total iron for all sensors studied, the orbital sensors despite the lower spectral resolution, maintained the characteristics of the soil and the curves of reflectance intensity.

Key words: remote sensing, pedology, soil attributes.

\section{INTRODUÇÃO}

Técnicas rápidas e de baixo custo para o diagnóstico in situ do solo e seus atributos são de grande valia para a avaliação e o manejo do solo. O uso de técnicas de sensoriamento remoto e de sistema de informação geográfica introduziu nova era no acesso e monitoramento dos recursos de solo no que se refere à qualidade da informação (Mermut e Eswaran, 2001).

No sensoriamento remoto, o conhecimento preliminar do comportamento espectral do alvo é de fundamental importância para a geração de informaçóes, a partir da interpretaçáo de imagens orbitais e para a análise quantitativa (Melendez-PAStor et al., 2008).

O comportamento espectral do solo depende diretamente de sua composição química, biológica, física e mineralógica (SousA Junior et al., 2008) resultante de fatores e processos atuantes na sua formaçáo; segundo STONER e BAumgardner (1981), a reflectância do solo é uma propriedade cumulativa derivada do comportamento espectral inerente da combinação heterogênea de seus componentes, como tamanho de partícula, estrutura do solo, rugosidade superficial, umidade, teor de matéria orgânica, teor de minerais carbonatados, presença ou não de quartzo e dos óxidos de Fe.

No nível orbital, o satélite mais utilizado para monitoramento é o Landsat, porém, com o fim de sua vida útil, outros satélites e sensores vêm sendo buscados para ocupar seu lugar e, dentre os vários existentes, tem-se o sensor ASTER do satélite TERRA com grande potencial visto que possui características similares ao Landsat. 
Pouca informação se tem sobre os solos brasileiros avaliados pelo ASTER, sendo de importância avaliar a resposta do solo com este sensor assim como compará-lo com o Landsat e com os dados radiométricos. Desta forma, este trabalho teve por objetivo caracterizar e comparar o comportamento espectral de diferentes classes de solo obtidos de sensores orbitais e terrestres.

\section{MATERIAL E MÉTODOS}

O trabalho foi realizado no município de Rafard (SP), em uma área de 184 ha margeada pelo Rio Capivari e delimitada pelas coordenadas geográficas $23^{\circ} 0^{\prime} 31,37^{\prime \prime}$ a $22^{\circ} 58^{\prime} 53,97^{\prime \prime}$ de latitude sul e $53^{\circ} 39^{\prime} 47,81^{\prime \prime}$ a $53^{\circ} 37^{\prime} 25,65^{\prime \prime}$ de longitude oeste. O clima local é caracterizado como mesotérmico de inverno seco (Centro Nacional de Ensino e Pesquisa Agronômica, 1960) e a geologia constituída de arenitos, argilitos e folhelhos do Grupo Tubarão (Formação Itararé) e basaltos do Grupo São Bento (Formação Serra Geral) (IPT, 1981).

Os 184 ha da área de estudo foram estaqueados em grade regular de $100 \times 100 \mathrm{~m}$, gerando 184 pontos georreferenciados para a coleta de solo, na profundidade de 0-20 $\mathrm{cm}$. As amostras de terra coletadas foram secas em estufa a $50{ }^{\circ} \mathrm{C}$ por 48 horas e peneiradas $(2 \mathrm{~mm})$; na fração menor que $2 \mathrm{~mm}$ foram efetuadas as análises físicas e químicas.

A análise física determinou os teores de areia, silte e argila a partir do método do densímetro (CAMARGo et al., 1986) e as químicas o $\mathrm{pH}$ em água e $\mathrm{KCl}, \mathrm{Ca}^{2+}, \mathrm{Mg}^{2+}$, $\mathrm{Al}^{3+}, \mathrm{H}^{+}+\mathrm{Al}^{3+}$, matéria orgânica (MO), de acordo com Raij e Quaggio (1989), ferro total $\left(\mathrm{Fe}_{2} \mathrm{O}_{3}\right)$, sílica $\left(\mathrm{SiO}_{2}\right)$ e titânio $\left(\mathrm{TiO}_{2}\right)$ pelo ataque sulfúrico, através de método descrito por CAMARgo et al. (1986). A partir dos dados químicos, foram obtidas a soma de bases (S), capacidade de troca catiônica (CTC), saturação por bases (V\%) e saturação por alumínio ( $\mathrm{m} \%)$.

Os solos da área foram classificados em Latossolo Vermelho-Amarelo distrófico típico (LVAd), Latossolo Vermelho-Amarelo eutrófico típico (LVAe), Latossolo Vermelho eutrófico típico (LVe), Latossolo Vermelho distrófico típico (LVd), Argissolo Vermelho-Amarelo eutrófico típico (PVAe), Argissolo Vermelho-Amarelo eutrófico abrúptico (PVAeab), Argissolo Vermelho-Amarelo distrófico típico (PVAd), Argissolo Vermelho-Amarelo distrófico abrúptico (PVAdab), Cambissolo Háplico Ta eutrófico típico (CXve), Cambissolo Háplico Tb eutrófico típico (CXbe), Cambissolo Háplico Tb distrófico típico (CXbd), Neossolo Litólico eutrófico típico (RLe), Neossolo Flúvico Tb eutrófico típico (RUbe) e o Neossolo Flúvico psamítico típico (RUq) (Nanni e Demattê, 2006).

As informações espectrorradiométricas foram coletadas das amostras de terra, secas e peneiradas, acondicionadas em placas de petri de $9 \mathrm{~cm}$ de diâmetro, utilizando-se o sensor IRIS (Infra Red Intelligent Spectroradiometer) com resoluçáo espectral de $2 \mathrm{~nm}$ (de 400-1000 nm) e de $4 \mathrm{~nm}(1000-2500 \mathrm{~nm})$.

A geometria do sistema baseou-se no posicionamento perpendicular do sensor em relação à amostra, mantendo entre ambos uma distância de $27 \mathrm{~cm}$. A fonte de iluminação foi posicionada a $61 \mathrm{~cm}$ da amostra, formando um ângulo de $20^{\circ}$ com o zênite. O padrão de referência absoluto utilizado foi uma placa de espectralon branca. A razão espectral entre o fluxo de radiação refletido pela superfície de referência e a amostra gerou o fator de reflectância bidirecional (Nicodemus et al., 1977).

Para a obtenção dos dados orbitais foram utilizadas duas imagens de sensores distintos, TM-Landsat 5 e ASTER-TERRA. Da imagem Landsat, com data de passagem em 27 de agosto de 1997 e órbita/ponto 220/076, utilizaram-se as bandas 1, 2, 3, 4, 5 e 7 e da imagem ASTER, com data de passagem de 6 de agosto de 2004, foram utilizadas as bandas $1,2,3,4,5,6,7$ e 8 .

Inicialmente, realizou-se a conversáo dos níveis de cinza para reflectância, e nas imagens de satélite Landsat utilizou-se o programa 5S (TANRÉ et al., 1992) e o programa ACORN (AIG, 2001) para ASTER. Na sequência, foi feita a correção geométrica das imagens no programa ENVI (RSI, 2005), utilizando-se pontos de controle coletados na área de estudo com um GPS trimble PRO-XR, submétrico e pós-processado de acordo com os procedimentos descritos por CRósta (1992). Posteriormente, procedeu-se a coleta dos dados espectrais orbitais, sobrepondo-se a informaçáo dos pontos de amostragem nas imagens de satélite.

Após a obtenção dos dados espectrais, terrestre e orbital, as amostras de terra foram agrupadas de acordo com a classe de solo e curvas espectrais médias foram geradas para os três sensores.

Para verificar estatisticamente as diferenças observadas entre as curvas espectrais das classes de solo, realizou-se um teste de média para as bandas do sensor ASTER, TM e também para o sensor IRIS. No caso do sensor IRIS, os dados espectrais foram avaliados simulando-se as bandas ASTER e TM, calculando-se o valor médio da reflectância referente à faixa de comprimento de onda de cada banda dos dois sensores. Para a realização desta análise, utilizou-se o programa Statistical Analysis System (SAS, 1999).

\section{RESULTADOS E DISCUSSÃO}

As curvas espectrais obtidas pelo sensor terrestre IRIS revelam de que forma os atributos do solo atuam sobre sua resposta espectral. Este efeito pode ocorrer causando bandas de absorção ou afetando a intensidade de reflectância das curvas. Os óxidos de ferro possem bandas de absorção em $530 \mathrm{~nm}$ para a hematita, $480 \mathrm{~nm}$ para a goetita e ainda uma banda em 900 nm, conforme verificado por Madeira NetTo (2001). Já a magnetita e a ilmetita não têm bandas de absorção, porém 
sua presença diminui a intensidade de reflectância por serem minerais opacos e de alta absorção (Hunt, 1979).

A matéria orgânica, por sua vez, afeta a resposta espectral dos solos diminuindo a intensidade de reflectância na faixa de 400 a $2500 \mathrm{~nm}$. Ademais, sua presença pode recobrir os óxidos de ferro existentes no solo afetando as bandas de absorção destes minerais (DEMATTÊ et al., 2003).

Em relação aos minerais de argila de solos, uma parte dos trabalhos tem sido direcionada ao estudo da caulinita e minerais 2:1, entre eles a montmorilonita. A curva de reflectância para tais minerais possui bandas centradas em 1400 e 2200 nm, devido às vibrações das moléculas de água e grupos $\mathrm{OH}$ das estruturas destes minerais. Como há moléculas de água entre as camadas unitárias na montmorilonita, bandas de absorçóes fortes ocorrem também em 1400 e 1900 nm (Hunt e SAlisbury, 1970), pois a banda em 1900 nm deve-se às vibraçóes de moléculas de água.

Assim, solos contendo dominância de caulinita possuem bandas de absorção fracas em 1400 e 1900 nm (Figura 1a). No caso da maior presença de minerais 2:1,

(a)

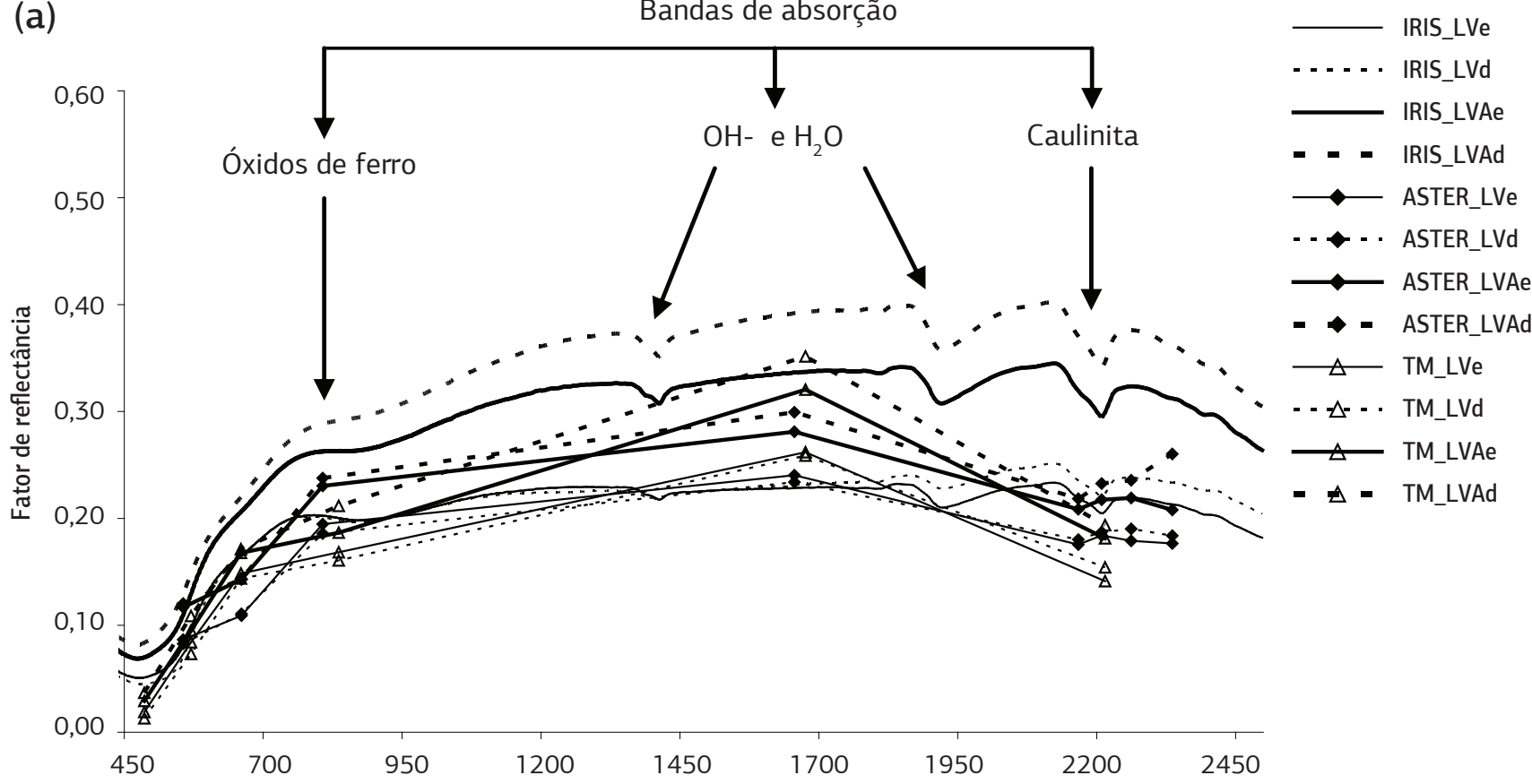

(b)

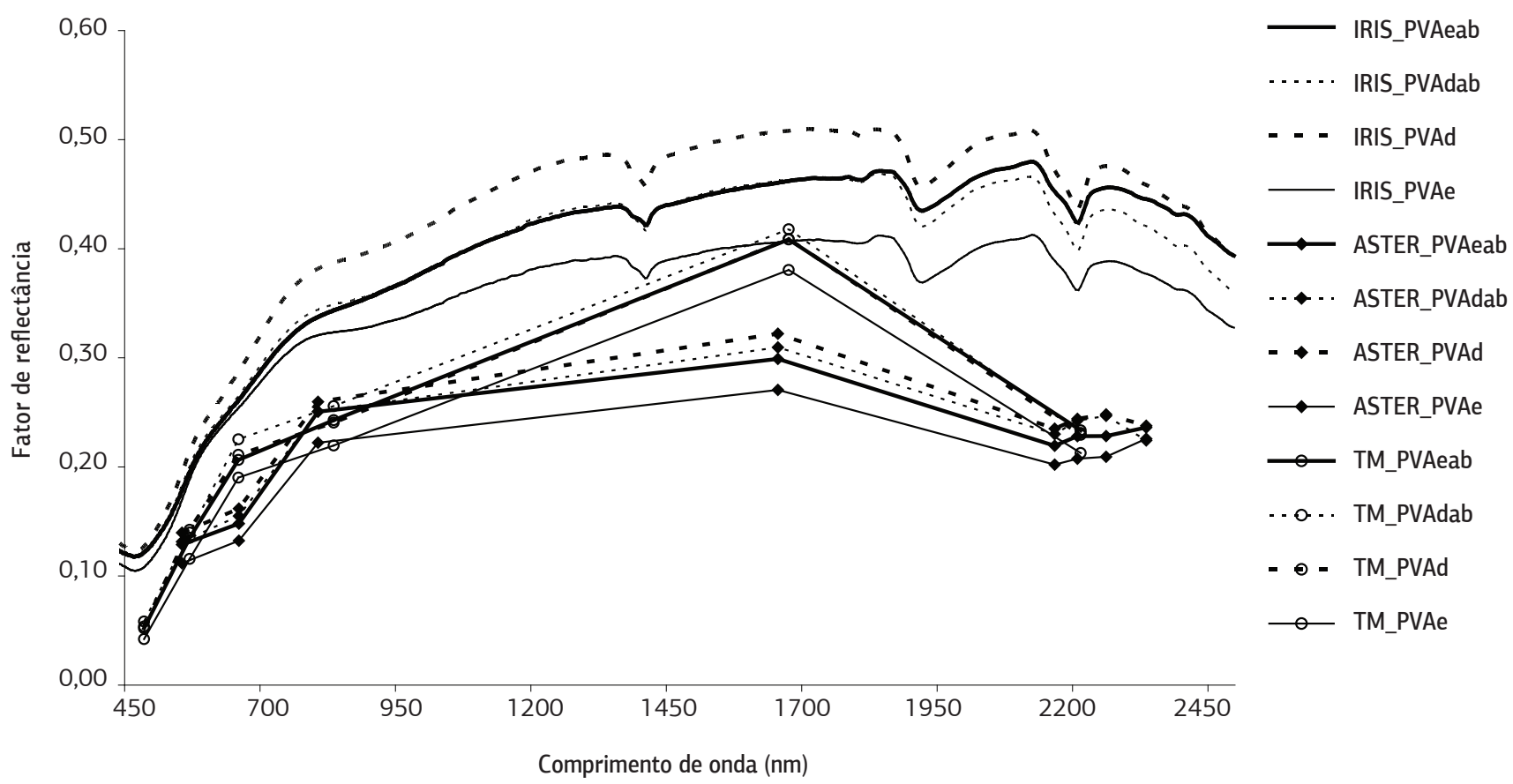

Figura 1. Curvas espectrais médias dos Latossolos (a) e Argissolos (b), obtidas pelos sensores IRIS (terrestre), ASTER e TM (orbitais). 
como a montmorilonita, a intensidade das bandas de absorção em 1400 e em $1900 \mathrm{~nm}$ vai ser maior do que em um solo caulinítico.

Para a gibbisita, a banda de absorção ocorre em $2265 \mathrm{~nm}$, também ocasionada pela ligaçáo $\mathrm{Al}-\mathrm{OH}$ (Madeira Netto e Baptista, 2000). Já a textura, afeta a intensidade da resposta espectral. Solos mais argilosos absorvem mais energia e refletem menos ao contrário dos solos mais arenosos que, devido à presença de quartzo, refletem a energia eletromagnética (Genú e DemattÊ, 2006).

Passando do nível terrestre para o orbital, diminui-se a resolução espectral (diminuição do número de bandas) com consequente alteração da forma da curva espectral. Tal fato ocasiona uma curva com perda de detalhes, no caso, as bandas de absorção não aparecem (Figura 1a), porém pode-se analisar a resposta espectral orbital através da intensidade de reflectância das curvas.

As curvas espectrais dos Latossolos, obtidas pelos três sensores estudados, podem ser inicialmente analisadas com relaçáo à cor do solo, os vermelhos (LVe e LVd) e os vermelho-amarelos (LVAe e LVAd).

Nas curvas IRIS dos Latossolos Vermelhos observa-se intensidade de reflectância mais baixa que nos VermelhoAmarelos devido à presença de minerais opacos como a ilmenita e magnetita. Estes minerais, derivados de rochas máficas, como os basaltos existentes na área, são caracterizados por sua alta absorçáo da energia eletromagnética em toda a faixa do espectro (Fontes e Carvalho Júnior, 2005). Verifica-se também para os Latossolos Vermelhos que a banda de absorção em $900 \mathrm{~nm}$ relativa aos óxidos de ferro (Madeira Netto, 2001) é mais intensa do que para os Latossolos Vermelho-Amarelos.

Através das curvas espectrais ASTER para os Latossolos, apesar de não ser possível observar as bandas de absorção como na curva IRIS, observa-se que os solos VermelhoAmarelos possuem intensidade de reflectância maior que os solos vermelhos em todo o espectro (Figura 1a), como verificado para as curvas IRIS. A resposta verificada para o sensor ASTER e IRIS também pode ser observada nas curvas obtidas pelos sensores TM (Figura 1a).

Verifica-se que a curva do Latossolo VermelhoAmarelo distrófico (LVAd) reflete mais que a do Latossolo Vermelho-Amarelo eutrófico (LVAe), principalmente na faixa do infravermelho médio, para os três sensores analisados (Figura 1a). O que pode influenciar esta resposta mais alta do Latossolo distrófico é o fato de este solo possuir textura mais arenosa e teor de ferro total menor que o distrófico (Tabela 1). De maneira geral, solos mais arenosos tendem a ter maior intensidade de reflectância, devido à sua constituição mineralógica (geralmente rica em quartzo) e também aos baixos teores de ferro (RESENDE et al., 2005).

Com relação aos Latossolos Vermelhos distrófico (LVd) e eutrófico (LVe) nota-se nas curvas espectrais de todos os sensores avaliados que até, aproximadamente, 1600 $\mathrm{nm}$ (bandas TM5 e ASTER4) ambos os solos possuem intensidade de reflectância muito próximas, porém após este comprimento de onda, o distrófico passa a refletir mais que o eutrófico (Figura 1a). Este fato pode ser explicado pela textura mais argilosa do Latossolo eutrófico (Tabela 1). Já na faixa do infravermelho, as bandas de absorção relativas aos minerais de argila do solo e da água ocorrem de tal forma que solos mais argilosos tendem a absorver mais energia e ter intensidade de reflectância mais baixa, concordando com Demattê (2002). Estas bandas, no entanto, são facilmente observadas nas curvas IRIS (Figura 1a).

O comportamento espectral dos Argissolos (Figura 1b) tem menor intensidade de reflectância para o VermelhoAmarelo eutrófico (PVAe). Esse processo ocorre devido ao

Tabela 1. Média dos atributos, para a camada de $0-20 \mathrm{~cm}$, das classes de solos estudadas

\begin{tabular}{|c|c|c|c|c|c|c|c|c|c|c|c|c|c|c|c|c|}
\hline \multirow{2}{*}{ Solo ${ }^{(1)}$} & \multicolumn{2}{|c|}{$\mathrm{pH}$} & $\mathrm{Ca}^{++}$ & $\mathbf{M g}^{++}$ & $\mathrm{Al}^{+++}$ & $\mathbf{K}^{+}$ & CTC (2) & $\mathbf{V}^{(3)}$ & $\mathbf{m}^{(4)}$ & $\mathrm{MO}^{(5)}$ & $\mathrm{SiO}_{2}{ }^{(6)}$ & $\mathrm{Fe}_{2} \mathrm{O}_{3}{ }^{(7)}$ & $\mathrm{TiO}_{2}{ }^{(8)}$ & Argila & Areia & Silte \\
\hline & $\mathrm{KCl}$ & $\mathrm{H}_{2} \mathrm{O}$ & \multicolumn{5}{|c|}{$\left(\mathrm{mmol}_{\mathrm{c}} \mathrm{dm}^{-3}\right)$} & \multicolumn{2}{|c|}{$(\%)$} & \multicolumn{7}{|c|}{$\left(\mathrm{g} \mathrm{kg}^{-1}\right)$} \\
\hline PVAd & 4,9 & 5,4 & 15,1 & 10,3 & 5,3 & 1,6 & 57,0 & 47,4 & 16,1 & 9,4 & 45,5 & 17,0 & 3,5 & 157,1 & 667,2 & 175,7 \\
\hline PVAe & 4,4 & 5,3 & 37,0 & 17,2 & 6,5 & 2,5 & 87,3 & 64,2 & 10,3 & 13,7 & 73,0 & 33,0 & 6,8 & 239,5 & 314,6 & 445,9 \\
\hline PVAdab & 4,7 & 5,2 & 17,7 & 7,5 & 6,4 & 1,4 & 58,4 & 44,9 & 27,5 & 12,9 & 42,8 & 15,1 & 2,9 & 141,5 & 721,2 & 137,3 \\
\hline PVAeab & 5,0 & 5,7 & 23,5 & 13,6 & 2,0 & 1,6 & 57,1 & 69,6 & 6,6 & 9,1 & 38,3 & 19,4 & 4,9 & 126,2 & 718,8 & 155,0 \\
\hline CXve & 5,4 & 6,3 & 105,0 & 38,0 & 0,5 & 3,1 & 168,1 & 83,5 & 0,2 & 21,0 & 112,5 & 103,5 & 17,1 & 388,4 & 362,0 & 249,6 \\
\hline CXbe & 5,3 & 5,9 & 43,1 & 19,2 & 2,0 & 2,5 & 85,2 & 77,1 & 2,7 & 13,5 & 73,7 & 34,6 & 5,3 & 261,0 & 504,8 & 234,2 \\
\hline CXbd & 4,7 & 5,4 & 17,2 & 11,1 & 4,5 & 1,2 & 64,1 & 46,1 & 10,6 & 9,0 & 63,3 & 19,5 & 3,3 & 201,3 & 587,5 & 211,2 \\
\hline RLe & 4,5 & 5,8 & 102,0 & 29,7 & 2,3 & 3,4 & 169,0 & 80,5 & 2,2 & 17,0 & 115,3 & 99,3 & 17,1 & 388,6 & 403,1 & 208,3 \\
\hline RUbe & 4,8 & 5,5 & 29,0 & 11,0 & 4,9 & 2,0 & 68,1 & 58,5 & 13,7 & 13,0 & 60,6 & 18,7 & 5,1 & 181,0 & 577,8 & 241,2 \\
\hline $\mathrm{RUq}$ & 5,1 & 5,8 & 24,0 & 10,0 & 0,7 & 2,1 & 58,1 & 62,4 & 2,1 & 13,0 & 38,7 & 12,3 & 4,9 & 113,9 & 698,6 & 187,5 \\
\hline LVAd & 4,4 & 5,3 & 18,7 & 10,0 & 4,3 & 1,7 & 64,8 & 47,0 & 13,7 & 14,3 & 57,6 & 34,4 & 7,7 & 219,8 & 612,3 & 167,9 \\
\hline LVAe & 5,1 & 5,9 & 43,4 & 16,2 & 0,8 & 1,7 & 82,9 & 71,1 & 1,2 & 11,6 & 80,4 & 60,0 & 12,2 & 300,8 & 506,4 & 192,8 \\
\hline LVe & 4,9 & 5,7 & 48,0 & 16,6 & 0,6 & 1,2 & 100,3 & 65,3 & 0,9 & 16,6 & 107,7 & 136,4 & 26,3 & 499,9 & 356,9 & 143,2 \\
\hline LVd & 4,3 & 5,1 & 28,7 & 9,0 & 4,7 & 0,9 & 83,9 & 45,9 & 11,9 & 18,7 & 84,0 & 74,3 & 15,0 & 330,6 & 480,7 & 188,7 \\
\hline
\end{tabular}

(') Solos: PVAd: Argissolo Vermelho-Amarelo distrófico típico, PVAe: Argissolo Vermelho-Amarelo eutrófico típico, PVAdab: Argissolo Vermelho-Amarelo distrófico abrúptico, PVAeab: Argissolo Vermelho-Amarelo eutrófico abrúptico, CXve: Cambissolo Háplico Ta eutrófico típico, CXbe: Cambissolo Háplico Tb eutrófico típico, CXbd: Cambissolo Háplico Tb distrófico típico, RLe: Neossolo Litólico eutrófico típico, RUbe: Neossolo Flúvico Tb eutrófico típico, RUq: Neossolo Flúvico psamítico típico, LVAd: Latossolo Vermelho-Amarelo distrófico típico, LVAe: Latossolo Vermelho-Amarelo eutrófico típico, LVe: Latossolo Vermelho eutrófico típico, LVd: Latossolo Vermelho distrófico típico. ${ }^{(2)}$ Capacidade de troca catiônica. $\left({ }^{3}\right)$ Saturação por bases. $\left({ }^{4}\right)$ Saturaçấo por alumínio. $\left({ }^{5}\right)$ Matéria orgânica. $\left({ }^{6}\right)$ Sílica obtida pelo método do ataque sulfúrico. $\left({ }^{7}\right)$ Ferro total obtido pelo método do ataque sulfúrico. $\left(^{8}\right)$ Titânio obtido pelo método do ataque sulfúrico. 
maior teor de argila e maior teor de ferro total (Tabela 1), proporcionando maior absorção da energia eletromagnética e consequente diminuição da reflectância (FormagGIO et al., 1996). Pode-se verificar, ainda, na curva do sensor IRIS (Figura 1b), a banda de absorção em $900 \mathrm{~nm}$ indicativo dos óxidos de ferro e as feições da caulinita e da água.

Os sensores orbitais ASTER e TM revelam resposta espectral similar com relação à intensidade de reflectância das amostras. Na faixa do infravermelho, principalmente, ocorre alta reflectância, que está relacionada à mineralogia caulinítica e ao teor de matéria orgânica deste solo (Tabela 1).

$\mathrm{Na}$ sequência, os Argissolos abrúpticos (PVAdab e PVAeab) e o Argissolo Vermelho-Amarelo distrófico (PVAd) possuem curvas espectrais muito próximas (Figura 1b), tanto para o sensor ASTER como para o sensor TM, no qual as curvas se sobrepóem em todo o

(a)

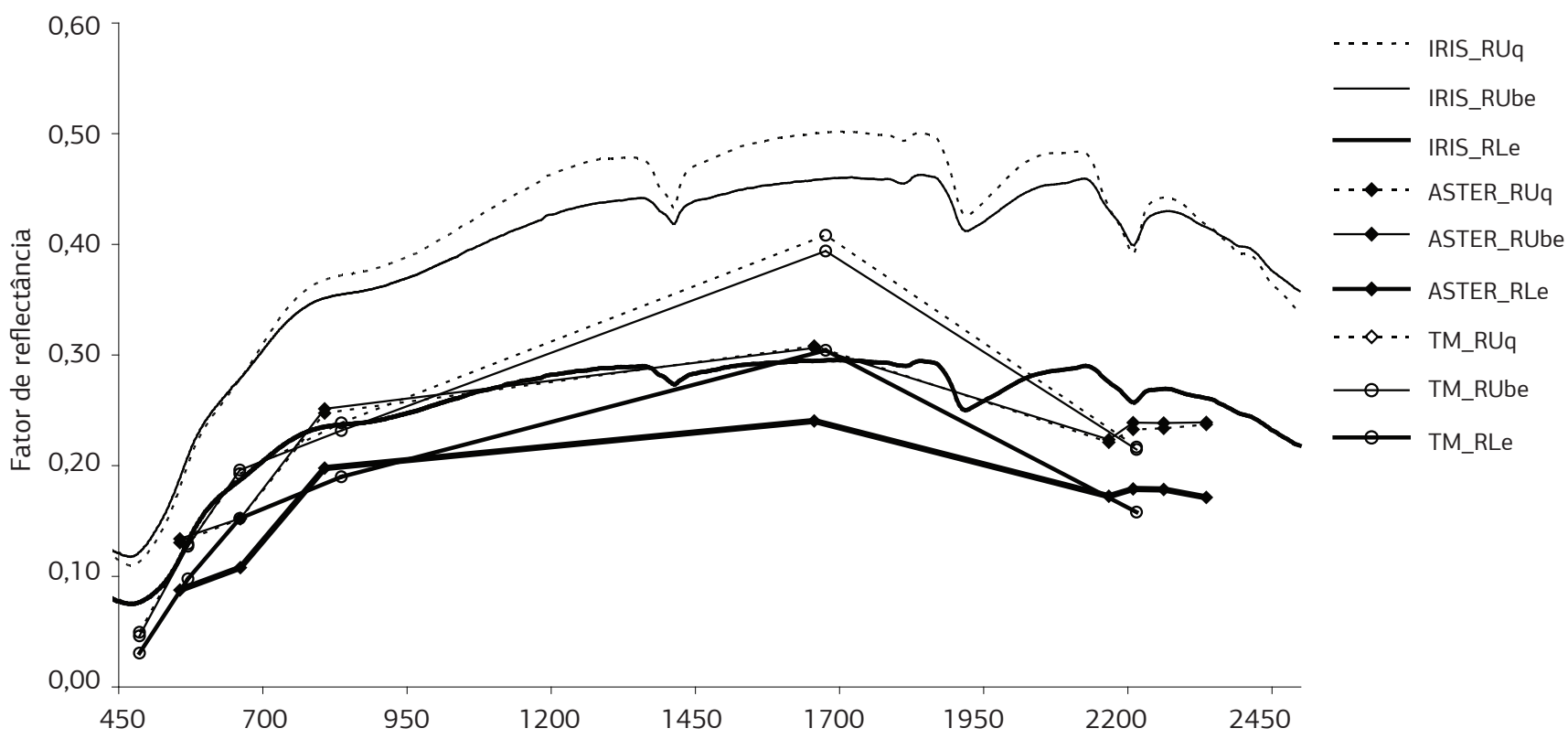

(b)

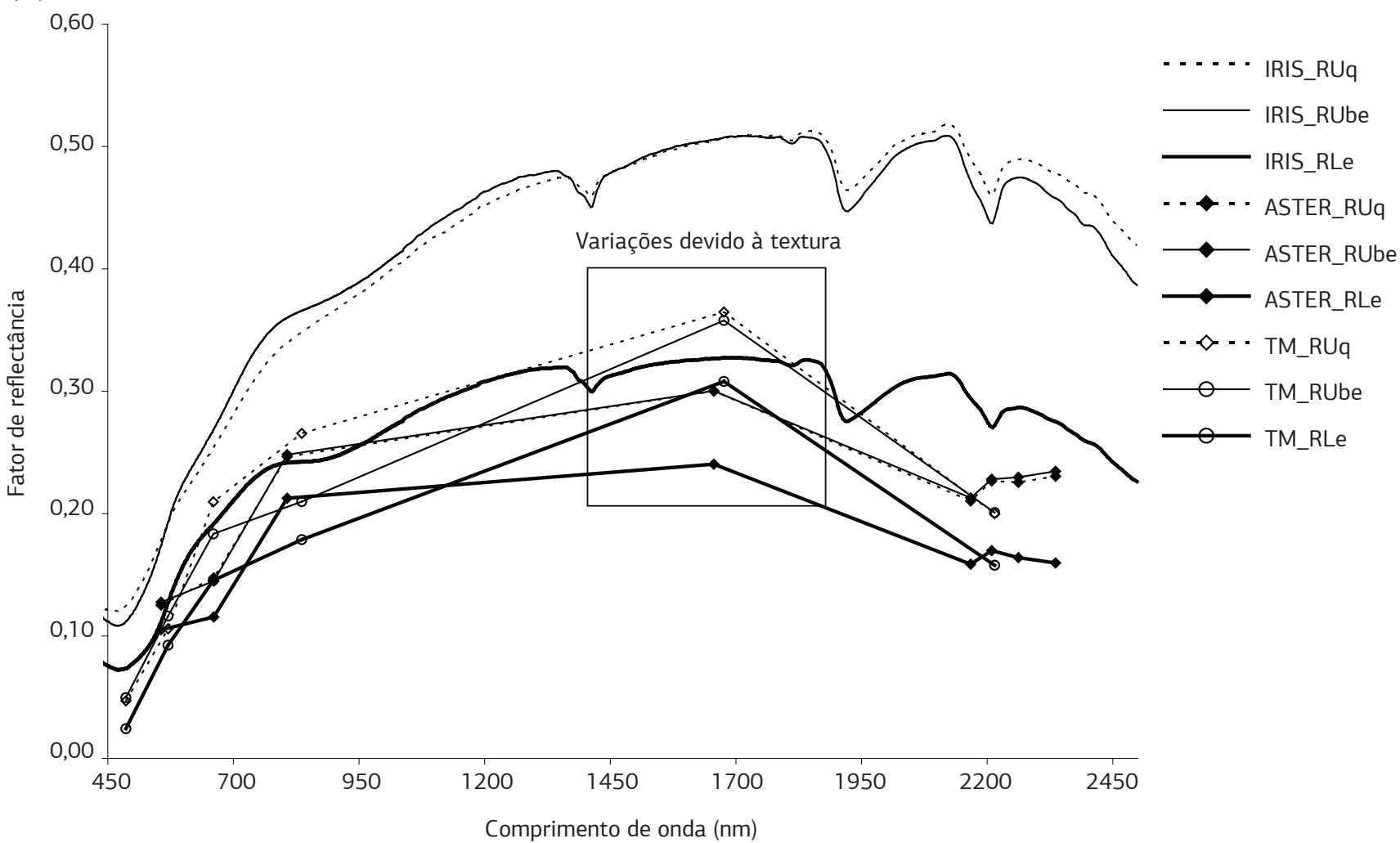

Figura 2. Curvas espectrais médias dos Cambissolos (a) e Neossolos (b), obtidas pelos sensores IRIS (terrestre), ASTER e TM (orbitais). 
espectro eletromagnético, pois nesses solos os teores de argila, matéria orgânica e ferro estão muito próximos (Tabela 1) causando esta similaridade entre as curvas.

Os Cambissolos Háplicos Tb (CXbd e CXbe) têm valores muito próximos de matéria orgânica, ferro total e argila (Tabela 1) e como resultado destas similaridades, suas curvas espectrais são também muito semelhantes (Figura 2a) em forma e intensidade. No sensor IRIS, é possível observar as bandas intensas da água e a da caulinita (Figura 2a), enquanto nas curvas orbitais, o comportamento é o mesmo em termos da intensidade de reflectância do solo. Por outro lado, as curvas do Cambissolo Ta (CXve) (Figura 2a) são facilmente discriminadas, pois têm baixa reflectância como resultado do seu alto teor de argila e ferro total que, como comentado anteriormente, proporciona alta absorção da energia incidente (DALmolin et al., 2005).

As curvas espectrais médias dos Neossolos Flúvicos (RU) propiciam alta intensidade de reflectância (Figura 2b), enquanto para o Neossolo Litólico (RLe) as curvas são de baixa intensidade (Figura 2b), sendo facilmente discriminadas. Este comportamento é, novamente, resultado dos maiores teores de ferro total, matéria orgânica e argila do Neossolo Litólico em relação aos Neossolos Flúvicos (Tabela 1).

$\mathrm{O}$ teste de média para as bandas dos sensores orbitais TM e ASTER, entre as classes de solos, mostrou que o Argissolo Vermelho-Amarelo distrófico (PVAd) foi o melhor discriminado dentre todos, com diferença estatística para o Cambissolo Ta (CXve) nas bandas ASTER 1, 4, 5, mas sem diferença nas bandas TM; para o Latossolo Vermelho eutrófico (LVe) nas bandas ASTER 1, 4 e TM 2, 7; para o Latossolo Vermelho distrófico (LVd) nas bandas ASTER 1, 3, 4 e TM 2, 5 e, para o Neossolo Litólico (RLe) nas bandas ASTER 4, 5, 6, 7, mas sem diferença nas bandas TM (Tabelas 2 e 3). Resultados similares foram obtidos para os dados do sensor terrestre IRIS, simulando as bandas dos sensores orbitais ASTER e TM-Landsat (Tabelas 2 e 3).

Os Latossolos Vermelhos (LVe e LVd), Neossolo Litólico e Cambissolo Ta (CXve) são solos mais argilosos,

Tabela 2. Teste de média para classes de solo a partir das bandas do sensor ASTER e do sensor IRIS simulado para ASTER

\begin{tabular}{|c|c|c|c|c|c|c|c|c|}
\hline Solo (1) & ASTER 1 (2) & ASTER 2 & ASTER 3 & ASTER 4 & ASTER 5 & ASTER 6 & ASTER 7 & ASTER 8 \\
\hline \multicolumn{9}{|c|}{ ASTER ${ }^{(4)}$} \\
\hline PVAd & $0,1397 a^{(3)}$ & $0,1617 a$ & $0,2597 a$ & $0,3221 a$ & $0,2350 a$ & $0,2440 a$ & $0,2482 a$ & $0,2377 a b c$ \\
\hline PVAe & $0,1116 a b c$ & $0,1324 a$ & $0,2222 a b$ & $0,2706 a b$ & $0,2021 a b c$ & $0,2076 a b$ & $0,2093 a b$ & $0,2258 a b c$ \\
\hline PVAdab & $0,1291 a b c$ & $0,1524 a$ & 0,2466ab & 0,3049ab & $0,2271 a b$ & 0,2394ab & $0,2431 a$ & $0,2222 a b c$ \\
\hline PVAeab & $0,1288 a b c$ & $0,1480 a$ & $0,2506 a b$ & 0,2990ab & $0,2193 a b c$ & $0,2282 a b$ & $0,2283 a b$ & $0,2361 a b c$ \\
\hline CXve & $0,0876 b c$ & $0,1078 a$ & $0,1978 a b$ & $0,2404 b$ & $0,1723 b c$ & $0,1790 a b$ & $0,1785 a b$ & $0,1713 b c$ \\
\hline CXbe & $0,1339 a b$ & $0,1523 a$ & $0,2513 a b$ & $0,3063 a b$ & $0,2236 a b$ & $0,2388 a b$ & $0,2385 a$ & $0,2391 \mathrm{ab}$ \\
\hline CXbd & $0,1304 a b c$ & $0,1519 a$ & $0,2474 a b$ & $0,3081 a b$ & $0,2211 \mathrm{ab}$ & $0,2327 a b$ & $0,2337 a b$ & $0,2372 a b c$ \\
\hline RLe & $0,1051 a b c$ & $0,1156 a$ & $0,2126 a b$ & $0,2404 b$ & $0,1587 c$ & $0,1697 b$ & $0,1640 b$ & $0,1597 c$ \\
\hline RUbe & $0,1276 a b c$ & $0,1449 a$ & $0,2481 a b$ & $0,3003 a b$ & $0,2129 a b c$ & $0,2281 a b$ & $0,2297 a b$ & $0,2346 a b c$ \\
\hline $\mathrm{RUq}$ & $0,1252 a b c$ & $0,1475 a$ & $0,2466 a b$ & $0,3001 \mathrm{ab}$ & $0,2103 a b c$ & $0,2266 a b$ & $0,2255 a b$ & $0,2305 a b c$ \\
\hline LVAd & $0,1203 a b c$ & $0,1432 a$ & $0,2377 a b$ & 0,2993ab & $0,2184 a b c$ & $0,2326 a b$ & $0,2357 a b$ & $0,2603 a$ \\
\hline LVAe & $0,1168 a b c$ & $0,1429 a$ & $0,2305 a b$ & $0,2811 a b$ & $0,2085 a b c$ & $0,2175 a b$ & $0,2192 a b$ & $0,2079 a b c$ \\
\hline LVe & $0,0866 b c$ & 0,1090a & $0,1946 a b$ & $0,2404 b$ & $0,1755 a b c$ & $0,1841 a b$ & 0,1790ab & $0,1765 b c$ \\
\hline LVd & $0,0828 c$ & $0,1107 a$ & $0,1858 b$ & $0,2340 b$ & $0,1802 \mathrm{abc}$ & $0,1871 a b$ & 0,1902ab & $0,1838 a b c$ \\
\hline \multicolumn{9}{|c|}{ IRIS - ASTER (5) } \\
\hline PVAd & $0,2003 a$ & $0,2877 a$ & $0,3805 a$ & $0,5068 \mathrm{a}$ & $0,4752 a b$ & $0,4469 a b$ & $0,4742 a$ & $0,4602 a b$ \\
\hline PVAe & $0,1757 a b c$ & $0,2545 a b c d$ & 0,3196abcd & $0,4057 a b c d$ & 0,3910abcd & 0,3695abcd & $0,3873 a b c$ & $0,3782 \mathrm{abcd}$ \\
\hline PVAdab & $0,1883 a b$ & $0,2660 a b c$ & $0,3432 a b c$ & $0,4616 a b c$ & $0,4347 a b c$ & $0,4085 a b c$ & $0,4344 a b$ & $0,4220 a b c$ \\
\hline PVAeab & $0,1858 \mathrm{ab}$ & $0,2626 a b c$ & $0,3381 \mathrm{abcd}$ & $0,4638 a b c$ & $0,4573 a b$ & $0,4346 a b$ & $0,4570 a$ & $0,4484 a b$ \\
\hline CXve & $0,1257 \mathrm{abcd}$ & $0,1938 \mathrm{bcd}$ & 0,2410 cde & $0,3025 \mathrm{de}$ & 0,2859def & 0,2705 def & 0,2781 cde & 0,2708def \\
\hline CXbe & $0,2006 a$ & $0,2818 a b$ & $0,3545 a b$ & $0,4670 a b$ & $0,4425 a b c$ & $0,4166 a b c$ & $0,4374 a b$ & $0,4260 a b c$ \\
\hline CXbd & $0,1869 a b$ & $0,2791 a b$ & $0,3665 a b$ & $0,4996 a$ & $0,4382 a b c$ & $0,4045 a b c$ & $0,4401 a b$ & $0,4202 a b c$ \\
\hline RLe & $0,1096 \mathrm{~cd}$ & $0,1830 \mathrm{~cd}$ & 0,2297de & 0,3135 cde & 0,2817def & 0,2628 def & 0,2722 cde & 0,2622 def \\
\hline RUbe & $0,1804 a b c$ & $0,2692 a b c$ & $0,3592 a b$ & $0,5053 a$ & $0,4746 a b$ & $0,4467 a b$ & $0,4730 a$ & $0,4591 \mathrm{ab}$ \\
\hline RUq & $0,1823 a b c$ & $0,2544 a b c d$ & 0,3394abcd & $0,5045 a$ & $0,4923 a$ & $0,4683 a$ & $0,4882 a$ & $0,4790 a$ \\
\hline LVAd & $0,1293 a b c d$ & $0,2118 a b c d$ & 0,2740abcde & 0,3722abcde & 0,3572bcde & 0,3355bcde & $0,3583 a b c d$ & 0,3471bcde \\
\hline LVAe & $0,1196 \mathrm{bcd}$ & $0,2068 \mathrm{abcd}$ & $0,2617 \mathrm{bcde}$ & $0,3360 \mathrm{bcde}$ & $0,3217 c d e f$ & 0,3029cdef & 0,3224 bcde & 0,3132 cdef \\
\hline LVe & $0,0899 d$ & $0,1655 d$ & $0,2014 \mathrm{e}$ & $0,2284 \mathrm{e}$ & $0,2204 f$ & $0,2090 f$ & $0,2186 \mathrm{e}$ & $0,2135 f$ \\
\hline LVd & $0,0812 d$ & $0,1641 d$ & $0,1999 e$ & $0,2309 e$ & $0,2368 \mathrm{ef}$ & $0,2253 f$ & 0,2377de & $0,2339 \mathrm{ef}$ \\
\hline
\end{tabular}

(1) Solos: PVAd: Argissolo Vermelho-Amarelo distrófico típico, PVAe: Argissolo Vermelho-Amarelo eutrófico típico, PVAdab: Argissolo Vermelho-Amarelo distrófico abrúptico, PVAeab: Argissolo Vermelho-Amarelo eutrófico abrúptico, CXve: Cambissolo Háplico Ta eutrófico típico, CXbe: Cambissolo Háplico Tb eutrófico típico, CXbd: Cambissolo Háplico Tb distrófico típico, RLe: Neossolo Litólico eutrófico típico, RUbe: Neossolo Flúvico Tb eutrófico típico, RUq: Neossolo Flúvico psamítico típico, LVAd: Latossolo Vermelho-Amarelo distrófico típico, LVAe: Latossolo Vermelho-Amarelo eutrófico típico, LVe: Latossolo Vermelho eutrófico típico, LVd: Latossolo Vermelho distrófico típico. ${ }^{(2)}$ ASTER1....ASTER8: Bandas do sensor ASTER. $\left({ }^{3}\right)$ Médias com a mesma letra na coluna, entre todos os solos, nāo diferem significativamente pelo teste de Tukey a 5\%. ${ }^{(4)}$ Resultados obtidos para as bandas do sensor ASTER. ( $\left.{ }^{5}\right)$ Resultados obtidos para as bandas do sensor ASTER simuladas pelo sensor IRIS. 
com maior teor de matéria orgânica e maior teor de ferro total, quando comparados com o Argissolo VermelhoAmarelo distrófico (PVAd) (Tabela 1), causando intensidade de reflectância mais baixa para aqueles solos e sendo a razão para esta diferenciação.

As bandas ASTER 1 e TM 2 proporcionam a mesma faixa do espectro eletromagnético, de 520 a $600 \mathrm{~nm}$. Neste intervalo ocorre uma feição espectral da hematita devido à transição eletrônica de campo cristalino deste óxido de ferro (Sherman e Waite, 1985). O efeito desta banda está relacionada à diminuição da intensidade de reflectância. Como aqueles solos são mais vermelhos que o Argissolo Vermelho-Amarelo distrófico (PVAd), tal fato explica a discriminaçáo dos solos nestas bandas.

As bandas ASTER 4, 5, 6, 7 e TM 5, 7 que ocorrem na faixa do infravermelho médio, estáo relacionadas à presença dos minerais da fração argila e à granulometria do solo. A banda TM 7 integra as feições espectrais da caulinita e gibbsita; assim como as bandas ASTER 5, 6 e 7 apesar disso, tais minerais não podem ser discriminados pelos satélites. Esses minerais são os principais componentes da fração argila destes solos e, portanto, de boa correlaçáo com o teor de argila e a maior absorção nestas bandas (MAderia NetTo e BAptista, 2000). Já as bandas ASTER 4 e TM 5, apesar de não terem nenhuma feição específica relacionada aos minerais da fração argila, mostram nas curvas tendência mais inclinada na direção das bandas ASTER 5 e TM 7 (Figuras 1 e 2), devido ao solo ser mais argiloso (Maderia Netto e Baptista, 2000). A banda ASTER 3, por sua vez, está relacionada à banda de absorção da água, que promove uma diminuiçáo na intensidade de reflectância, diferenciando os solos.

Tabela 3. Teste de média para classes de solo a partir das bandas do sensor TM e do sensor IRIS simulado para TM

\begin{tabular}{|c|c|c|c|c|c|c|}
\hline Solo ${ }^{(1)}$ & TM $1^{(2)}$ & TM 2 & TM 3 & TM 4 & TM 5 & TM 7 \\
\hline \multicolumn{7}{|c|}{$\mathrm{TM}^{(4)}$} \\
\hline PVAd & $0,0537 a b^{(3)}$ & $0,1423 a$ & $0,2110 a b$ & $0,2406 a b c d$ & 0,4090a & $0,2294 a$ \\
\hline PVAe & 0,0421 abcd & $0,1156 a b c$ & $0,1902 a b$ & 0,2196abcde & $0,3805 a b c$ & $0,2127 a b$ \\
\hline PVAdab & $0,0583 a$ & $0,1398 a b$ & $0,2253 a$ & $0,2557 a b$ & $0,4179 a$ & $0,2310 a$ \\
\hline PVAeab & $0,0521 a b$ & $0,1350 a b$ & $0,2064 a b$ & $0,2429 a b c$ & $0,4085 a$ & $0,2335 a$ \\
\hline CXve & 0,0306abcd & $0,0976 a b c$ & $0,1523 b$ & $0,1899 \mathrm{bcde}$ & $0,3042 a b c$ & $0,1579 a b$ \\
\hline CXbe & $0,0461 a b c$ & $0,1271 a b c$ & $0,1960 a b$ & 0,2317abcde & 0,3939ab & $0,2146 a b$ \\
\hline CXbd & $0,0494 a b c$ & $0,1292 a b c$ & $0,1927 a b$ & $0,2386 a b c d$ & $0,4081 a$ & $0,2167 a b$ \\
\hline RLe & $0,0242 \mathrm{bcd}$ & $0,0925 a b c$ & $0,1454 b$ & 0,1787 cde & $0,3080 a b c$ & $0,1578 a b$ \\
\hline RUbe & $0,0496 a b$ & $0,1163 a b c$ & $0,1834 a b$ & 0,2098abcde & $0,3578 a b c$ & $0,2008 a b$ \\
\hline RUq & $0,0470 a b c$ & $0,1058 \mathrm{abc}$ & $0,2096 a b$ & $0,2656 a$ & $0,3647 a b c$ & $0,2000 a b$ \\
\hline LVAd & 0,0369abcd & $0,1087 a b c$ & $0,1712 a b$ & 0,2117abcde & $0,3515 a b c$ & $0,1937 a b$ \\
\hline LVAe & $0,0292 \mathrm{abcd}$ & $0,0951 a b c$ & $0,1677 a b$ & 0,1867 bcde & $0,3205 a b c$ & $0,1813 a b$ \\
\hline LVe & $0,0189 \mathrm{~cd}$ & $0,0842 b c$ & $0,1485 b$ & 0,1683 ed & $0,2619 b c$ & $0,1412 b$ \\
\hline LVd & $0,0130 d$ & $0,0732 c$ & $0,1437 b$ & $0,1607 e$ & $0,2588 c$ & $0,1542 a b$ \\
\hline \multicolumn{7}{|c|}{ IRIS - TM (5) } \\
\hline PVAd & $0,1316 a$ & $0,2003 a$ & $0,2877 a$ & $0,3846 a$ & $0,4891 a$ & $0,4748 a b$ \\
\hline PVAe & $0,1121 a b c$ & $0,1757 a b c$ & $0,2545 \mathrm{abcd}$ & $0,3217 a b c d$ & 0,3936abcd & $0,3886 a b c d$ \\
\hline PVAdab & $0,1252 a b$ & $0,1883 a b$ & $0,2660 a b c$ & $0,3466 a b c$ & $0,4446 a b c$ & $0,4348 a b c$ \\
\hline PVAeab & $0,1268 a b$ & $0,1858 a b$ & $0,2626 a b c$ & $0,3427 a b c d$ & $0,4462 a b c$ & $0,4573 a b$ \\
\hline CXve & 0,0801 abcd & $0,1257 \mathrm{abcd}$ & $0,1938 \mathrm{bcd}$ & 0,2424 cde & 0,2957de & 0,2812 def \\
\hline CXbe & $0,1307 a$ & $0,2006^{a}$ & $0,2818 a b$ & $0,3576 a b$ & $0,4514 a b$ & $0,4394 a b c$ \\
\hline CXbd & $0,1175 a b c$ & $0,1869 a b$ & $0,2791 a b$ & $0,3695 a b$ & $0,4798 a$ & $0,4400 \mathrm{abc}$ \\
\hline RLe & $0,0684 c d$ & $0,1096 \mathrm{~cd}$ & $0,1830 \mathrm{~cd}$ & 0,2306de & 0,3053 cde & 0,2765 def \\
\hline RUbe & $0,1156 a b c$ & $0,1804 a b c$ & $0,2692 a b c$ & $0,3636 a b$ & $0,4842 a$ & $0,4741 \mathrm{ab}$ \\
\hline $\mathrm{RUq}$ & $0,1275 a b$ & $0,1823 a b c$ & $0,2544 a b c d$ & $0,3460 a b c$ & $0,4812 a$ & $0,4901 \mathrm{a}$ \\
\hline LVAd & 0,0804abcd & 0,1293abcd & $0,2118 a b c d$ & 0,2760abcde & 0,3576abcde & 0,3580bcde \\
\hline LVAe & $0,0724 \mathrm{bcd}$ & $0,1196 \mathrm{bcd}$ & $0,2068 \mathrm{abcd}$ & 0,2626 bcde & 0,3271 bcde & 0,3223 cdef \\
\hline LVe & $0,0530 d$ & $0,0899 d$ & $0,1655 d$ & $0,2005 e$ & $0,2271 e$ & $0,2195 f$ \\
\hline LVd & $0,0465 d$ & $0,0812 d$ & $0,1641 d$ & $0,1989 e$ & $0,2265 e$ & $0,2378 \mathrm{ef}$ \\
\hline
\end{tabular}

(') Solos: PVAd: Argissolo Vermelho-Amarelo distrófico típico, PVAe: Argissolo Vermelho-Amarelo eutrófico típico, PVAdab: Argissolo Vermelho-Amarelo distrófico abrúptico, PVAeab: Argissolo Vermelho-Amarelo eutrófico abrúptico, CXve: Cambissolo Háplico Ta eutrófico típico, CXbe: Cambissolo Háplico Tb eutrófico típico, CXbd: Cambissolo Háplico Tb distrófico típico, RLe: Neossolo Litólico eutrófico típico, RUbe: Neossolo Flúvico Tb eutrófico típico, RUq: Neossolo Flúvico psamítico típico, LVAd: Latossolo Vermelho-Amarelo distrófico típico, LVAe: Latossolo Vermelho-Amarelo eutrófico típico, LVe: Latossolo Vermelho eutrófico típico, LVd: Latossolo Vermelho distrófico típico. (2) TM1....TM7: Bandas do sensor TM-Landsat. ${ }^{(3)}$ Médias com a mesma letra na coluna, entre todos os solos, nâo diferem significativamente pelo teste de Tukey a 5\%. $\left({ }^{4}\right)$ Resultados obtidos para as bandas do sensor TM-Landsat. $\left({ }^{5}\right)$ Resultados obtidos para as bandas do sensor TM-Landsat simuladas pelo sensor IRIS. 


\section{CONCLUSÕES}

O sensor IRIS devido à alta resolução espectral permitiu a diferenciação das classes de solo estudadas assim como identificar os atributos que mais afetam o comportamento espectral dos solos. Os sensores orbitais, apesar de não permitirem a observação de bandas de absorção devido à sua resolução espectral, também foram capazes de distinguir classes sendo a textura, matéria orgânica e ferro total os principais atributos responsáveis por esta diferenciação. Os sensores TM e ASTER comparados com o sensor IRIS proporcionaram resposta espectral similar quanto à intensidade de reflectância dos solos estudados.

\section{REFERÊNCIAS}

ANALYTICAL IMAGING AND GEOPHYSICS - AIG. Atmospheric correction now (ACORN) 3.12. Boulder, 2001. CDROM.

CAMARGO, A.O.; MONIZ, A.C.; JORGE, J.A.; VALADARES, J.M. Métodos de análise química, mineralógica e física de solos do IAC. Campinas: IAC, 1986. 94p. (IAC, Boletim Técnico, 106)

CENTRO NACIONAL DE ENSINO E PESQUISA AGRONÔMICA. Levantamento de reconhecimento de solos do Estado de São Paulo. Rio de Janeiro: Ministério da Agricultura, 1960. 637p. (SNPA, Boletim 12)

CRÓSTA, A.P. Processamento digital de imagens de sensoriamento remoto. Campinas: UNICAMP, 1992. 170p.

DALMOLIN, R.S.D.; GONÇALVES, C.N.; KLAMT, E.; DICK, D.P. Relaçáo entre os constituintes do solo e seu comportamento espectral. Ciência Rural, v.35, p.481-489, 2005.

DEMATTÊ, J.A.M. Characterization and discrimination of soils by their reflected electromagnetic energy. Pesquisa Agropecuária Brasileira, v.37, p.1445-1458, 2002.

DEMATTÊ, J.A.M.; EPIPHANIO, J.C.N.; FORMAGGIO, A.R. Influência da matéria orgânica e de formas de ferro na reflectância de solos tropicais. Bragantia, v.62, p.451-464, 2003.

FONTES, M.P.F.; CARVALHO JUNIOR, I.A. Color attributes and mineralogical characteristics, evaluated by radiometry, of highly weathered tropical soils. Soil Science Society of America Journal, v.69, p.1162-1172, 2005.

FORMAGGIO, A.R.; EPIPHANIO, J.C.N.; VALERIANO, M.M.; OLIVEIRA, J.B. Comportamento espectral (450-2450 nm) de solos tropicais de Sáo Paulo. Revista Brasileira de Ciência do Solo, v.20, p.467-474, 1996.

GENÚ, A.M.; DEMATTÊ, J.A.M. Determination of soil attribute contents by means of reflected eletromagnetic energy. International Journal of Remote Sensing, v.27, p.4807-4818, 2006.

HUNT, G.R. Spectral signatures of particulate minerals in the visible and near infrared. Geophysics, v.42, p.501-513, 1979.
HUNT, G.R.; SALISBURY, J.W. Visible and near infrared spectra of minerals and rocks I: Silicate minerals. Modern Geology, v.1, p.283-300, 1970.

INSTITUTO DE PESQUISAS TECNOLÓGICAS - IPT. Divisão de Minas e Geologia Aplicada. Mapa geológico de Estado de São Paulo. São Paulo, 1981. Escala 1:1.000.000.

MADEIRA NETTO, J. S. Comportamento espectral dos solos. In: MENESES, P.R.; MADEIRA NETTO, J.S., (Org). Sensoriamento remoto: reflectância de alvo naturais. Brasília: Editora UnB; EMBRAPA Cerrados, 2001. p.127-156.

MADEIRA NETTO, J.S.; BAPTISTA, G.M.M. Reflectância espectral de solos. Planaltina: EMBRAPA Cerrados, 2000. 55p.

MELENDEZ-PASTOR, I.; NAVARRO-PEDREÑO, J.; GÓMEZ, I.; KOCH, M. Identifying optimal spectral bands to assess soil properties with VNIR radiometry in semi-arid soils. Geoderma, v.147, p.126-132, 2008.

MERMUT, A.R.; ESWARAN, H. Some major developments in soil science since the mid-1960s. Geoderma, v.100, p.403-426, 2001.

NANNI, M.R.; DEMATTÊ, J.A.M. Spectral Reflectance Methodology in Comparison to Traditional Soil Analysis. Soil Science Society of America Journal, v.70, p.393-407, 2006.

NICODEMUS, F.E.; RICHMOMD, J.C.; HSIA, J.J.; GINSBERG, I.W.; LIMPERIS, T. Geometrical considerations and nomenclature for reflectance. Washington: US Department of Commerce, 1977.52 p. (NBS Monograph, 160)

RAIJ, B. van.; QUAGGIO, J.A. Métodos de análise de solo para fins de fertilidade. Campinas: IAC, 1989. 40p. (IAC, Boletim Técnico 8)

RESEARCH SYSTEMS INC. ENVI 4.1., 2005. Boulder, 2005. CD-ROM.

RESENDE, M.; CURI, N.; KER, J.C.; REZENDE, S.B. Mineralogia de solos brasileiros: interpretação e aplicaçóes. Lavras: Editora UFLA, 2005. 192p.

SHERMAN, D.M.; WAITE, T.D. Eletronic spectra of Fe oxides and oxide hydrocxides in the near IR to near UV. American Mineralogist, v.70, p.1262-1269, 1985.

SOUSA JUNIOR, J.G.; DEMATTÊ, J.A.M.; GENÚ, A.M. Comportamento espectral dos solos na paisagem a partir de dados coletados por sensores terrestre e orbital. Revista Brasileira de Ciência do Solo, v.32, p.727-738, 2008.

STONER, E.R.; BAUMGARDNER, M.F. Characteristics variations in reflectance of surface oils. Soil Science Society of America Journal, v.45, p.1161-1165, 1981.

STATISTICAL ANALYSIS SYSTEM. SAS 8.02. Cary, 1999. CDROM.

TANRÉ, D.; HOLBEN, B.N.; KAUFMAN, Y.J. Atmospheric correction algorithm for NOAA-AVHRR products: theory and application. IEEE Transactions on Geoscience and Remote Sensing, v.30, p.231-248, 1992. 